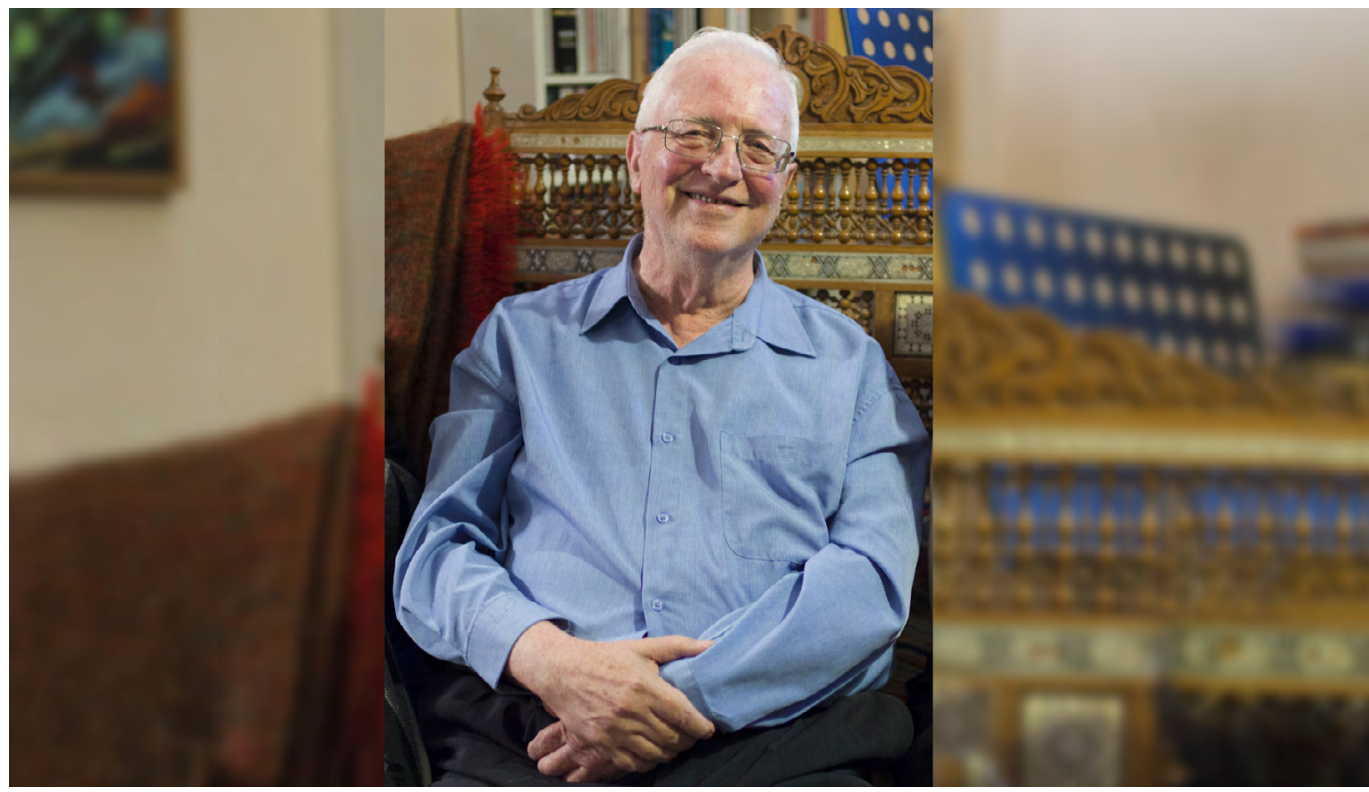

Daniel Kane. PC: Andrea Cavazzuti.

\section{A Tribute to Daniel Kane}

Annie Luman REN

first met Daniel Kane, or Danny as he was known to friends, during a week-long symposium on Manchu culture and literature that took place inside a grand country house in South Wairarapa, New Zealand, in 2018. The purpose of that gathering was to discuss the acquisition of Chinese language, thought, and art by the Manchus and, by extension, the need for the same kind of cultivation by scholars, artists, and translators engaging with China today. Danny was brought in not only as an expert on the Jurchen and Manchu languages, but also as a Sinologist trained in the very best tradition.

The event's organisers, John Minford and Geremie Barmé, had hoped that by bringing older established scholars like Danny together with young scholars and translators like myself, the Sinological tradition could be passed down and take on new forms, just as the Manchus had helped to transform and rejuvenate the very tradition they sought to acquire. Modelling their symposium on the famous gathering at Orchid Pavilion-a refined and convivial gathering of scholars and artists in $353 \mathrm{CE}$, dedicated to the enjoyment of friendship, poetry, and wine-the organisers wrote: 
It is our hope that 'in this throng of men and women of distinction, this congregation of young and old, with drinking and the chanting of verses, we may converse in whole-hearted freedom, and enter fully into one another's deeper feelings'.

They were quoting freely from Wang Xizhi, the famed calligrapher who was present at the gathering at Orchid Pavilion and who was entrusted with the task of writing a preface to the collection of poems composed on that day. Wang was truly in an inspired state when he penned his preface. Later on, he made hundreds of attempts to reduplicate his own masterpiece, but never succeeded in equalling the miraculous beauty of the original (Ryckmans 1989: 2). Despite the fact that Wang's original manuscript had long ceased to exist (if imperial records can be trusted, Emperor Tang Taizong took it with him to his grave), we can continue to admire the sublime beauty of his writing through rubbings taken from engraved stone-tablets.

In a similar way, Danny Kane's distinguished career as a specialist on the Khitan language and script and his legacy will ultimately be tied to rubbings taken from the stone-tablet in front of Empress Wu Zetian's mausoleum, which today is a mere hour's drive from that of Emperor Taizong. Before she created her own dynasty, Wu was a member of Taizong's imperial consort and, after his death, she married his son Gaozong. Wu famously instructed that a blank stele be erected at the entrance to her tomb, inviting future historians to judge her actions and deeds. It was not until the late nineteenth century that two parallel texts were found on the very top of this supposedly blank stele: one script is unquestionably Chinese; the other, it later transpired, is Khitan. It is largely based on the rubbing of the bilingual text that scholars like Danny Kane could begin to decipher the Khitan script.

Just as he was beginning to unravel this peculiar form of writing that had long ceased to exist, Danny was also deciphering a language that is very much alive. Working for the Australian Embassy in Beijing from 1976 to 1980, he became fascinated by the cursive scripts on large posters that were beginning to appear on the walls of the city. Driven by the same kind of enthusiasm that propelled him to learn Italian, Spanish, and French as a child, Danny soon mastered what he termed 'political Chinese', as well as the Beijing dialect, through reading these 'big character posters'. Danny was able to use his insight to report on political developments in post-Mao China. During the brief period of political liberation known as the 'Beijing Spring', he translated Wei Jingsheng's posters on the Democracy Wall for foreign reporters.

Danny's linguistic gift was truly astonishing. When asked how he came to speak so many languages, he just shrugged his shoulders and said: 'You just pick it up.' The ease with which he acquired new languages is reminiscent of Paul Pelliot, the brilliant French Sinolo- 
gist and explorer, who is said to have mastered a new language while waiting for his luggage to arrive in Tashkent. But for those who have met Danny, it was his eagerness to communicate with people using his natural gift for which he will always be remembered. Chris Nailer, a mutual friend of ours, told me the following story. In 1971, during his second year at Melbourne University, Chris was hospitalised after a motorbike accident and Danny, then a fourth-year student, would visit him regularly in the hospital ward. The patient in the opposite bed was an immigrant from Turkey, who spoke almost no English. Being a keen language learner himself, Chris asked a friend to bring in a copy of 'Teach Yourself Turkish' and a dictionary. The next day, Danny arrived to visit; seeing the Turkish books and hearing the story, he bounded across the ward with his hand in the air, greeting the patient in his irrepressibly jovial manner: 'Nazilsiniz? [How are you?].' The two remained in conversation for quite some time, before Danny turned to Chris and said: 'Well, we ran to the end of my Turkish rather quickly but found we could converse in a mixture of Bulgarian and Greek!'

I shall never forget the reason Danny gave for why some languages cease to exist. 'When a language becomes dead or is going to die, it becomes simplified,' he observed. 'Let's say, for example, that in classical Manchu there are a dozen or so words for "cup", such as chalice, goblet, pannikin, et cetera. But, by the end of the Qing Dynasty, people have forgotten the other terms; they just know the one word, "cup". 'I see this happening now in our society', he added. 'Kids these days may say: "Yeah, but you don't know the way we speak." But in ten years from now, all the words that I have in my head will be gone.'

Danny had already been diagnosed with Parkinson's disease when he agreed to be interviewed. Perhaps he wanted to preserve some of the 'words in his head'. My colleague Ivan Franceschini and I visited him at his home near Macquarie University in Sydney and recorded the interview on 9 September 2019. We had planned to publish it the following month but, after reading the transcript, Danny wrote to me and said he wished to rewrite it (on this, a friend remarked: 'That's so typical of Danny').

I never got to the bottom of this; perhaps he thought it sounded too informal, too much like a friendly chat since I deliberately preserved his natural way of speaking. After waiting for some months, I called him to see how he was doing. He told me he had fractured his foot and had been in hospital for months. That was

[1] My thanks to Christopher Nailer for a written account of the story. In our recent email exchange (23 April 2021), Chris wrote: 'The story illustrates not only Danny's good grasp of multiple languages, but it also illustrates his exuberance and his drive to engage and to communicate with other people-it didn't matter what language the other person spoke, Danny would find some combination of languages that he knew that would make communication possible.' 
the last time we spoke. I had planned to visit him in March 2020, but by then Australia had entered into a nationwide COVID-19 lockdown. I tried to get in touch during those months of isolation, but his phone was off. It was only earlier this year that I heard his health had deteriorated and he had been moved to an aged care facility in Melbourne to be closer to family. Danny passed away on 16 April 2021 surrounded by loved ones.

I was hesitant about publishing this interview, fearing it may be against Danny's wishes. But reading it over again, I was struck by how gracious he sounded and how at ease he appeared to be. Had he been in better health, the interview might have turned out to be more polished, more like the discerning voice of Daniel Kane, the esteemed linguist. For this, readers can easily turn to the impressive oeuvre he leaves behind (see the list of publications at the end). I do believe, despite its unvarnished state, the interview succeeds in capturing an inspired moment-one that sadly can no longer be reduplicated. Here we have the voice of our dear friend Danny, 'conversing in wholehearted freedom'.

Daniel Kane: I was really into languages even when I was young. I used to ask kids at school-some were from Poland, some from Hungary-and I would ask: 'How do you count from one to ten?' There were many Italian kids at my primary school, so I learnt quite a bit of Italian. I also learnt Latin at that time in the church and, when I went to high school, I studied Latin more formally and also French. It was a very multicultured environment and most people spoke something else other than English.

Then, for various personal reasons, I left school when I was 16 and I got a job working in a bank on Lygon Street, which was 'Little Italy'. This suited me fine. I was speaking Italian all day, occasionally French and by that stage I had also learnt quite a bit of Spanish. You know, there were lots of migrants around. I had no ambition, didn't know what ambition was, really. Then, by accident, someone from the university came in one day and we got chatting in Italian, and he said to me, 'Why are you working at a bank?' And I said, 'Oh, it pays the bills.' To which he said, 'Why don't you go to the university?' For me, university was where people go to become doctors or lawyers. The person said, 'Come to my office and we will talk about it.' He turned out to be the dean of the arts faculty.

To cut a long story short, after sitting for the entry exams, I was admitted to Melbourne University without a clear idea why I was there. But I knew I wanted to get into languages-the more exotic, the more unusual, the harder, the better. So, I decided to study Chinese and Russian on the grounds that Chinese was hard and Russian was pretty tough, too. I did those two languages for four 
years. I did other subjects, too, which was mind-blowing, because in those days people read a lot. For Russian, we had to read all of Chekhov, a lot of Tolstoy and Dostoevsky; even in Chinese it was like that. In the first year, we learnt some basic Chinese but in the second year we were all reading some very hard stuff. But for me, I just couldn't get enough of it.

\section{AR: What was it like to be studying Chinese in Australia in the 1960s and 1970s? Was there anyone whom you particularly admired or who encouraged you in your studies?}

DK: In Melbourne, we had a very literary course, in which we were studying the most outstanding works of Chinese literature for over 2,000 years. In our second year, we had to read essays by Hu Shi; there's one called 'The Significance of the New Ideas' [“新思潮的意 義']. We also read a story by Ba Jin called 'Moon Night' ['月夜'], and writings by Lu Xun such as 'Hometown' [“故鄉']. We read classical stuff like Water Margin [水潡傳] and Dream of the Red Chamber [ 紅樓夢]. In our third year, we read more of the Dream of the Red Chamber and Tang poetry, and in our fourth year we read Song lyric poetry. And people actually liked that stuff a lot. They didn't really learn to speak Chinese because at that time you couldn't really go to China, so there wasn't any practical use to learn Chinese. When you went to open day, generally speaking, people doing Japanese would say they wanted to do business or find a job in Japan, but if you asked students studying Chinese back then, they all had unpractical ideas. Someone may be a Buddhist; another guy may be interested in kung-fu. I remember one retired woman whose ambition was to read Dream of the Red Chamber: she didn't even want to speak Chinese.

At Melbourne, we used to spend our days in the library, which wasn't actually a library, just a room where people would hang out. It was a very egalitarian place because the lecturers and professors occasionally would come and sit down and chat about this and that. And the students would help each other out, so if you were a firstyear student reading a text that you couldn't understand, you could ask a third-year student who had done that particular text for help. So, people were very close. Some of my best friends are from that period; it was a very happy place to be.

The Australian National University [ANU] was sort of like that, except basically there weren't any undergraduate students there. But there were postgraduates, and they were all very interesting people and doing all sorts of strange things. Every morning and every afternoon, we had teatime and people would just go to the tearoom and sit down for five or 10 minutes and chat or gossip or say hello. 
DK: I graduated with first-class honours from Melbourne University and I was offered a PhD scholarship at the ANU. So I went, but at that time I didn't have any clue on what I wanted to do, except that I wanted to do something about the history of the Chinese language. I got interested in the history of Yuan Dynasty Chinese, because, by then, people had been working a lot on Tang Dynasty Chinese and pre-Tang Chinese and of course early modern Chinese. My supervisor was Professor Liu Ts'un-yan [柳存仁], but he didn't know what to make of me.

So I was just working my way on Yuan Dynasty Chinese, looking at books such the Rhymes of the Central Plain [中原音韻]-a book on the pronunciation of spoken Chinese in the Yuan Dynasty-when somehow Igor found out about it and he came to me and said he was happy to help. At that time, a discovery had been made about the Etruscan language, which was used in places like Tuscany. Igor of course knew all about this and I was very interested because I was into that sort of thing. It was probably at that time that Igor said to me that, if I was really interested in dead languages, I should look into Khitan. He also recommended a book on the history of the Liao Dynasty by Wittfogel and Feng. I managed to find a copy in the library; it was a very fat book and it was absolutely wonderful because it included everything that was known about Khitan, like their customs and culture, but not about their language because nobody knew anything then. This was also when my background in languages came in, because I could read all the articles on ancient Chinese written in Russian, French, and so on.

European scholars like Igor got into their heads that Khitan was some sort of Mongol, but I don't believe it is the case. Perhaps I'm the only one on Earth, because I'm an empiricist and I see no real proof of that yet. I had a theory that Khitan is related to Jurchenspoken by the people who established the Jin Dynasty after the Liao. So, I thought that if we could work out the relationship between Khitan and Jurchen, then we'll know, but it turned out I couldn't do it. It's only much later that I found I was on the right track. In the end, I wrote a book on the Jurchen language instead, because it had something to do with Khitan and also I had to write a PhD thesis. I couldn't just write down all the things I hadn't proved.

As for Igor, he was a very gentle and proper sort of person. You could always go to him for a good story. Once we were talking about Canberra dinner parties and I asked him whether it had happened to him at dinner parties that people asked him what did he do and he said: 'Oh yes, all the time. My favourite answer was "I am a Mongolologist", and once some woman said: "Oh, do you breed the dogs?"” 

pen name, Simon Leys). Could you tell us about your friendship with him?

DK: With Pierre we got to be very good friends. You've got to learn French so you could really know Pierre because his French was just so gloriously beautiful, but it could also be so yi zhen jian xue [ 一針見血, poignant]; so nasty in a very subtle, funny sort of way. But he and I appreciated each other, he liked playing word games and puns and we would talk about French literature or Chinese history together. He once wrote me a highly unconventional reference letter in which he said: 'Dr Kane has more brains in his little finger than the rest of the faculty.' This was so typical of Pierre.

One of the huge fights Pierre had was with Stephen FitzGerald, the first [Australian] Ambassador to China. I went to China with the second ambassador, who is still a good friend of mine. When FitzGerald came back from China, he was hot stuff because China was a closed country. He was invited to give a talk in the ANU Coombs Theatre and he made a speech saying that the Chinese were so happy, they loved the Communist Party and that China owes Chairman Mao so much and what not. Anyway, Pierre exploded. He got up and said: 'I will not let you say these callous lies, this is obscene what you are saying.' FitzGerald was also a wild guy; he started to attack Pierre and Pierre said: 'I challenge you: next week, you will appear here and I will prove to you that you are wrong.' So they had to get Wang Gungwu, who was the head of department, to convene the session. Wang was like the referee during a wrestling match. FitzGerald got up and said what he wanted to say, and Pierre started quoting Orwell, Locke, Chekhov ... Anyway, he made FitzGerald look like a completely uneducated person.

AR: For a while, after your PhD, you joined the Department of Foreign Affairs and were sent to Beijing in 1976. What was it like to be in China after the Cultural Revolution?

DK: By the time I finished my PhD, [Prime Minister Gough] Whitlam had established diplomatic relations with China and they needed young Australians who could speak Chinese to send to the new embassy in China. So, Canberra being Canberra, everyone knew everybody else. A friend from Melbourne recommended me for the job and I went to talk to them, and they sent me to China, where I stayed for four years. The first six months after I arrived were quite interesting because my Chinese was Chinese but it wasn't political Chinese, which was thoroughly incomprehensible. So they gave me six months to learn that sort of Chinese-you know, like 'destroy the Gang of Four' [粉碎四人短] and so on. I did a course on Chinese literature at Peking University, which was all about class struggle and peasant literature. It was also the time of 'open-door schooling' [開門辦學], so I went to work in a factory. 


\section{AR: You are an authority on the Khitan language. Can you tell us more about this language?} How were you finally able to decipher it?

DK: Khitan was the language spoken by the people who established the Liao Dynasty [907-1125] in northern China, which lasted for over two centuries. There are two types of Khitan script, the 'large script' [大字] and the 'small script' [小字]. Like I said, it was only much later did I discover that the 'large script' is in fact related to Jurchen. People still don't know where the 'small script' came from.

When I was in China, one day I read an advertisement in the Beijing Daily [北京日報] that the Cultural Palace of Nationalities [民族文化宫] was holding an exhibition on ancient scripts. There was a Khitanologist called Liu Fengzhu [刘凤菁], and I had read his articles but never got to meet him. Anyway, I went to this exhibition and there was a girl who was a master's student and I asked her if she could read what was on display and she said no, but she said her teacher could. So I asked: 'Who is your teacher?' And she said: 'Liu Fengzhu.' I said: 'Oh, I'd love to meet him, where can I find him?' And she said: 'Maybe he's gone home, hang on.' So she disappeared and came back about five minutes later with this old guy, and I asked: 'Are you Mr Liu Fengzhu?' And he said: 'Oh my god, how could you possibly know?'

You know, this foreigner just walks in and says are you so and so; it must have been quite terrifying. Anyway, we became very good friends and he gave me lots of stuff which nobody outside China could get. There's a Chinese saying on how a bad thing might lead to good consequences. During the Cultural Revolution, scholars like Liu Fengzhu were sent down to the May Seventh Cadre School 
[五七幹校]. While they were there, they had access to this rubbing and, because they had nothing else to do, they copied it out and they made tables between the Chinese and Khitan.

This rubbing is the Rosetta Stone [a bilingual stele written in ancient Greek and ancient Egyptian, in hieroglyphic and demotic scripts, which was the key to deciphering ancient Egyptian] of the Khitan language. It comes from the 'Tomb Without An Inscription' [無字碑] in front of Empress Wu Zetian's tomb, which, as it turns out, does actually have inscriptions on it. But they are on the top and are very hard to see. You can't read them unless you climb up on a ladder.

This rubbing is bilingual-Chinese on the left and Khitan on the right. You would normally think it would be child's play if you can understand Chinese, but this was not the case, because, when you look at it, the first two characters say 'Mighty Jin' [大金], so when

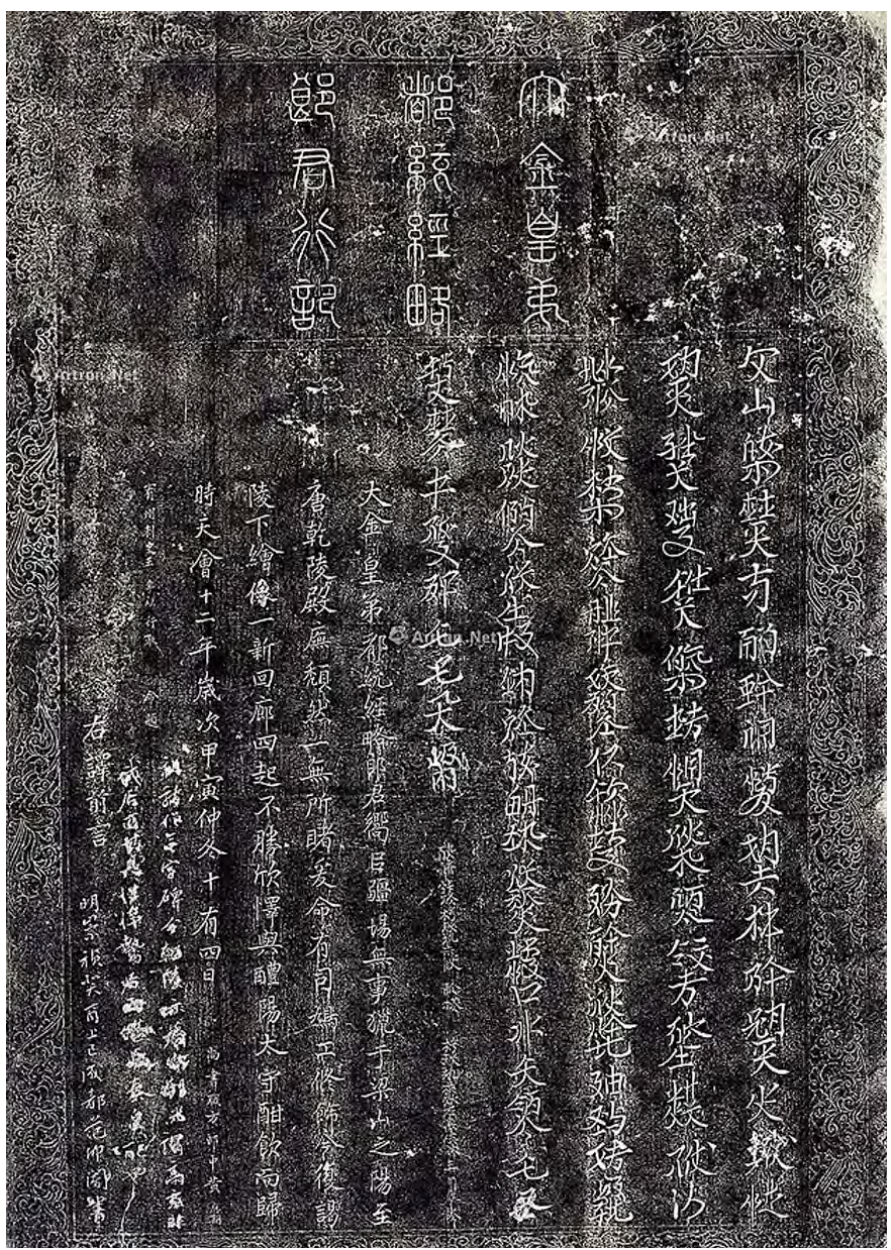


they first discovered this, people assumed this was written in the Jurchen script. It was only in the 1920s, when the tombs of the Liao emperors were discovered by tomb robbers near modern-day Chifeng in Mongolia, that people realised that it was Khitan. Even then, for a long time, scholars didn't get very far. You can read the dates and numbers so that's a start, but you don't know the pronunciation, you just know this squiggle means this. Towards the end, you have two official titles and names, but it later turned out that the Khitan version actually reversed the names, which caused a great deal of confusion for years.

By 1987, Chinese scholars had worked out a lot of pronunciations of the characters based on the name of the officials, and they were about 70 per cent right. But in the middle, there were three-quarters of the text where no-one knew what is going on. It is still the case today. So, when you asked how did I decipher the Khitan language, I didn't really decipher it. The thing that I could contribute is that I could write what the Chinese are writing in a language the European scholars could understand, and I could also write in Chinese stuff written by foreigners which the Chinese could then also understand. The problem with European scholars is that they didn't understand Chinese historical linguistics-now people are catching up-and the Chinese who were working on this were historians who didn't know much about languages. So, they had to basically wait for someone like me. One fellow summoned it up very well. He said that: 'Kane's book brings an end to one era of Khitan studies and starts a new one.'

AR: This may sound ignorant to you, but what is the difference between Jurchen and Manchu?

DK: The people who crossed the Great Wall at the end of the Ming Dynasty didn't call themselves Manchu; they were Jurchens [女真]. The problem is that, by then, the word Jušen/Jurchen had come to mean 'slave', so when they settled down after the second Emperor Hong Taiji [1592-1643], the emperor decided to change their name to Manchu [满洲]. He didn't really bother to explain why. There are different theories, but the short answer is nobody really knows. The 'national language' of the Manchus was very close to the language of the Jianzhou branch of the Jurchens, which was the dialect spoken by the Aisin Gioro clan that founded the Qing Dynasty.

\section{AR: Manchu language has long been endangered but is now being revived in academia and also in popular culture, thanks to popular Chinese TV shows set in the Qing Dynasty. What do you think about this latest development?}

DK: I wrote an article on this somewhere [Kane 1997]. The revival of Manchu began not long after the end of the Cultural Revolution. Although there are more people studying Manchu now, they don't really get past the first 10 or 20 words. I have met people in China 
who speak real Manchu, and there are young people in China who are reviving Manchu; they sort of know it in a written way, but they always write the same things over and over again.

AR: You are an expert on several dead or endangered languages. What is the importance of studying these languages today?

DK: That is an interesting question. There is one view-probably the majority view - that every language has its own way of looking at the world. Some cultures sense time differently; others have different perceptions of colours. That's all very interesting because we tend to take our own culture for granted. My own view is that it's just interesting. It's like: why do people learn Latin? Because they like to. For me personally, it's an antiquarian sort of thing. Even when I was young, I was interested in dead languages. I never really asked myself why I was interested in these things; I just was. I was at Peking University one time and there was an American professor of geology, a woman, [aged] about 50. I asked her how many girls were in her class when she was a student, because you didn't see a lot of female geologists back then. She said none. So, I asked: 'How come you got interested in geology?' She said: 'I don't know. When I was young, other kids would pick up a rock and throw it away, but I would pick up a rock and say jeez, this is interesting.'

Another point of interest is that when a language becomes dead or is going to die, it becomes simplified. You see it in languages like Manchu. Let's say, for example, that in classical Manchu there are a dozen or so words for 'cup', such as chalice, goblet, pannikin, et cetera. But, by the end of the Qing Dynasty, people have forgotten the other terms; they just know the one word, 'cup'. I see this happening now in our society, certainly with my kids. Nobody really uses 'chalice' or 'goblet' anymore. Kids these days may say: 'Yeah, but you don't know the way we speak.' But in 10 years from now, all the words that I have in my head will be gone.

\section{AR: Has academia changed in the decades since you first began your academic career?}

DK: Again, the person to ask would be Pierre. He wrote so eloquently about this in his essay 'An Idea of the University' [Leys 2011: 398]. For me, there is no academia; it just doesn't exist anymore. There are a few good scholars still floating around, very few, and then there are those who don't know anything. The whole world now is full of China Watchers; almost none of them speak a word of Chinese, let alone know anything about modern China.

In academia, you would be together with fellow thinkers-people who are interested in culture, philosophy, history, art, thinking about questions, coming up with answers, regardless of whether they are undergraduates, postgraduates, or professors. This was what academia was like. And, of course, back then we not only had 
Sinologists in our department; we had Professor Johns, who was a world expert on Indonesian and Malay, and we had a fellow called Basham, who was one of the greatest experts on the history of India. There were lots of people like this, who all lived in this sort of village; it was truly magic. But the whole thing fell apart.

\section{AR: In today's academic environment (or, as you say, nonexistent academic environment), do you think it is still possible for young scholars to undertake the kind of research you did on dead or endangered languages?}

DK: The short answer is no, for two reasons. First, by the time I retired in 2012, political correctness had already taken over the university. If I had stayed at Macquarie or elsewhere, I would certainly be attacked by those people. I got out just at the right time, because just before my retirement the Vice-Chancellor of Macquarie, where I was then working, left and was replaced by an American preoccupied with league tables and publication outputs and so on. Since then, your worth as a member of the academic community has been assessed on the basis of how many articles you have written, with the minimum being four articles a year. You can't just turn out papers like that, not to mention books or translations.

The Dream of the Red Chamber is a good example. I don't know how long it took David Hawkes and John Minford to translate this novel into English or how many hours they spent on it, but you need a huge amount of dedication and time. I had previously read Gladys Yang and Yang Xianyi's translation, but when I saw the first volume of Hawkes' translation, which he called The Story of the Stone, literally every sentence I would pai an jiao jue [拍案叫 絕, strike the table and shout bravo]. It was just so stunning: every word, every sentence had obviously been thought about for hours and hours. And the same goes for Joseph Needham's Science and Civilisation in China. Needham would never be able to do what he did in today's environment.

AR: What advice do you have for young scholars today?

DK: You have to 'cultivate your own garden', as they say. And many people do, and in the most unexpected places. Sometimes I'm surprised to meet students who are very impressive and knowledgeable despite the educational system. I went to Rome a couple of years ago and I visited John Keats' grave. There were some American students there too, and there was one American girl who was crying in front of Keats' grave, she was just pouring her heart out. I thought that was just so utterly amazing because, you know, a 20-year-old girl now could develop such an appreciation of Keats. 
This text is taken from Made in China Journal: Volume 6, Issue 1, 2021, edited by Ivan Franceschini and Nicholas Loubere, published 2021 by ANU Press, The Australian National University, Canberra, Australia.

doi.org/10.22459/MIC.06.01.2021.23 